\title{
Handgrip strength during admission for COPD exacerbation: impact on further exacerbation risk
}

Chi-Tai Lee ${ }^{1}$ and Ping-Huai Wang ${ }^{1,2^{*}}$

\begin{abstract}
Background: Low handgrip strength (HGS) is independently associated with a higher exacerbation risk in stable chronic obstructive pulmonary disease (COPD); however, the relationship between HGS while being admitted for COPD exacerbation and further exacerbation risk after discharge remains unclear.
\end{abstract}

Methods: We enrolled patients admitted for COPD exacerbation between January 2018 and June 2019. HGS tests were done within 3 days after admission. The primary endpoint was exacerbations within 12 months after the index admission, which needed emergency room visits or hospital admission. We analyzed the relationships among demographics, HGS, pulmonary function parameters, and acute exacerbation events.

Results: Among 43 enrolled patients, 31 (72.1\%) participants (HGSw) had HGS weakness (22.1 $4.1 \mathrm{~kg})$. The other 12 (27.9\%) participants (non-HGSw) had the strength of handgrips $33.7 \pm 3.1 \mathrm{~kg}$. HGSw group showed a significantly higher rate of emergency room visits within 6, 9, and 12 months after the index admission than non-HGSW group $(0.81 \pm 1.30$ vs. $0.08 \pm 0.29, p=0.045 ; 1.26 \pm 1.59$ vs. $0.17 \pm 0.38, P=0.019 ; 1.48 \pm 1.86$ vs. $0.25 \pm 0.62, P=0.027$, respectively). There was a trend to have higher admission rate within 9 and 12 months in HGSw group, which did not achieve statistical significance ( $0.77 \pm 1.38$ vs. $0.08 \pm 0.29, P=0.064 ; 0.94 \pm 1.56$ vs. $0.08 \pm 0.29, P=0.062$, respectively).

Conclusions: HGS weakness measured upon admission for COPD exacerbation was associated with a higher risk of exacerbation in the next year.

Trial registration ClinicalTrials.gov Identifier: NCT04885933.

Keywords: Handgrip strength, Chronic obstructive pulmonary disease, Exacerbation

\section{Background}

Chronic obstructive pulmonary disease (COPD) is characterized by persistent respiratory symptoms and airflow limitation, which is caused by the complex interactions among exposure to noxious particles or gases and various host factors, including genetic inheritance, airway hyperresponsiveness, or inadequate lung development $[1,2]$.

\footnotetext{
*Correspondence: pinghuaiwang@gmail.com

1 Division of Pulmonology, Department of Internal Medicine, Far Eastern

Memorial Hospital, New Taipei City 220, Taiwan, ROC

Full list of author information is available at the end of the article
}

COPD has caused a progressive health burden worldwide mostly due to increasing exposure to noxious particles and the aging population [3]. In Taiwan, the estimated COPD prevalence in individuals aged $>40$ years was approximately 6\% in 2013 [4]. Moreover, in 2013, chronic airway diseases were the seventh leading mortality cause in Taiwan, with an annual mortality rate of 33.2 per 100,000 population [5].

COPD not only presents lung function impairment but also extrapulmonary complications resulting from systemic inflammation that extends from chronic airway inflammation, including cardiovascular diseases,

(c) The Author(s) 2021. Open Access This article is licensed under a Creative Commons Attribution 4.0 International License, which permits use, sharing, adaptation, distribution and reproduction in any medium or format, as long as you give appropriate credit to the original author(s) and the source, provide a link to the Creative Commons licence, and indicate if changes were made. The images or other third party material in this article are included in the article's Creative Commons licence, unless indicated otherwise in a credit line to the material. If material is not included in the article's Creative Commons licence and your intended use is not permitted by statutory regulation or exceeds the permitted use, you will need to obtain permission directly from the copyright holder. To view a copy of this licence, visit http://creativecommons.org/licenses/by/4.0/ The Creative Commons Public Domain Dedication waiver (http://creativeco mmons.org/publicdomain/zero/1.0/) applies to the data made available in this article, unless otherwise stated in a credit line to the data. 
osteoporosis, and muscle atrophy [6]. Previous studies have shown that skeletal muscle dysfunction increases the risk of COPD morbidity and mortality. Compared with healthy individuals, patients with COPD show reduced strength of skeletal and respiratory muscles. Hamilton et al. reported that $70 \%$ of patients with chronic lung disease present with quadriceps muscle weakness [7]. Moreover, patients with moderate-to-severe COPD present with a $20-30 \%$ decrease in the quadriceps femoris muscle strength [8-10]. However, muscle dysfunction at COPD might be heterogeneous. Compared to upper limb, the impairment degree of lower limb muscle strength is more correlated with COPD severity [9]. But the possible mechanisms of upper limb weakness was more complicated than lower limbs. It might be associated with respiratory muscle asynchronization and dynamic hyperinflation, not only muscle wasting or impaired endurance caused by COPD, just like lower limbs [11]. Regarding ventilatory muscle function, patients with COPD present with a $30-40 \%$ decrease in the maximal diaphragm strength $[7,8]$. The heterogeneity and complex of muscle dysfunction in COPD need a simple tool as a good reflection of general muscle strength [12]

Handgrip strength (HGS), not only directly represents hand muscle strength but also is a good surrogate measurement for overall muscle strength [12-14]. Specifically, HGS of COPD patients is correlated with the strength of other muscles, including the quadriceps and respiratory muscles $[8,15]$. Not only the representative of muscle strength, the degree of the HGS impairment is associated with a decline in forced expiratory volume in one-second percentage of predicted value $\left(\mathrm{FEV}_{1} \%\right.$ of predicted value) and COPD Global Initiative for Chronic Obstructive Lung Disease (GOLD) grading $[16,17]$. Moreover, Martinez et al. found that a 1-kg reduction in HGS was associated with an increased risk of exacerbation by $5 \%$ in stable COPD [18].

However, HSG measurement in these previous studies mostly was for patients with stable COPD. Respiratory discomfort and physical weakness could negatively affect HGS on admission for acute exacerbation of COPD (AECOPD) [19]. To our knowledge, there has been scarce studies on the relationship between HGS in patients admitted with AECOPD and further exacerbation risk. This prospective study aimed to investigate the relationship between HGS in early stage of admissions for AECOPD and post-discharge exacerbation risk of the next year.

\section{Methods}

\section{Designs and participants}

We enrolled patients aged $>45$ years who were admitted for AECOPD. COPD was defined as an obstructive ventilatory defect $\left(\mathrm{FEV}_{1} / \mathrm{FVC}<0.7\right)$ based on pulmonary function tests along with smoking for $>15$ pack-years or a history of noxious gas exposure or the clinical impression by attending physicians in cases that spirometry data were missing. Acute exacerbation was defined as acute worsening of respiratory symptoms that results in additional therapy. We excluded patients with heart failure; permanent pacemaker or implantable cardioverter-defibrillator [20]; significant fluid retention, including edema, pleural effusion, or ascites; morbid obesity with BMI $>34$ [21]; use of noninvasive positive-pressure ventilators (NIPPV) use upon admission; structural lung defects by chest plain films, including significant tuberculosis sequelae, bronchiectasis, and pneumoconiosis; and readmission for AECOPD within 1 month. Participants received standard care based on the clinical judgments of attending physicians.

The COPD assessment test (CAT) questionnaire was simultaneously administered. Data regarding exacerbation occurrence with emergency room visits or even admission were obtained at three-month intervals through outpatient clinic follow-up visits, medical record or telephone interviews. The CAT questionnaire was re-administered at the third post-discharge month. The primary end-points were acute exacerbations leading to emergency room visits or readmission within 12 months after admission. This study was approved by the Institutional Review Board of Far Eastern Memorial Hospital (FEMH-10699-E). In addition, participants had to sign informed consents before initiating the study.

\section{Handgrip strength measurement}

HGS measurements were performed within 3 days of admission. HGS measurements were performed by using a dynamometer (North Coast Hydraulic Hand Dynamometer, North Coast Medical Inc., Morgan Hill, CA). The patient was seated with the wrist neutrally positioned and the elbow flexed at 90 degree[22]. For patients who were unable to sit, HGS measurements were obtained while lying in bed at $30^{\circ}$ with supported elbows. HGS was measured by the dominant hand of participants three times with the interval of at least one minute. The highest value was used in our analyses. HGS weakness (HGSw) was defined based on the guidelines of the European Working Group on Sarcopenia in Older People (EWGSOP) [23]. The patients were divided into the HGSw and non-HGSw groups, with cut-off HGS values of $<30 \mathrm{~kg}$ in men and $<20 \mathrm{~kg}$ in women [23].

\section{Measurement of skeletal muscle mass}

Skeletal muscle mass was assessed using a foot-to foot bioelectrical impedance analyzer (BIA) (TBF-410-GS 
Tanita, Japan). It was measured, following by the manufacture's instruction.

\section{Sarcopenia definition}

Sarcopenia was defined based on EWGSOP recommendations as follows: skeletal muscle index (skeletal muscle mass $/$ height ${ }^{2}$, SMI) of men was less than $8.87 \mathrm{~kg} / \mathrm{m}^{2}$ and that of women was $<6.42 \mathrm{~kg} / \mathrm{m}^{2}$ in conjugated to HGS weakness [23].

\section{Pulmonary function test}

Pulmonary spirometry data, including FEV1, forced vital capacity (FVC), and FEV1/FVC, were collected within 12 months before admission according to electronic

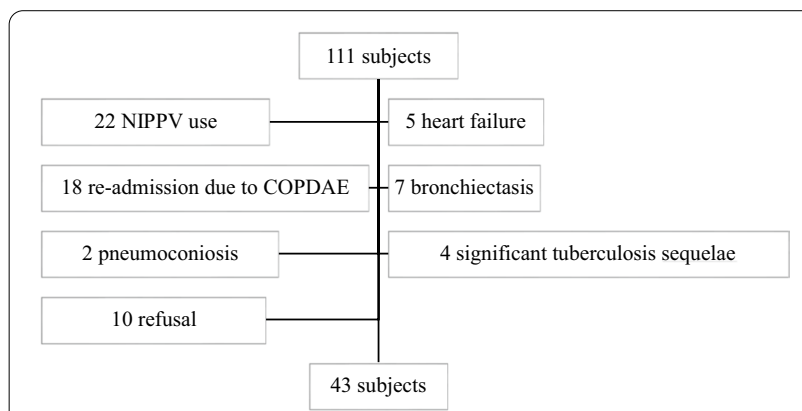

Fig. 1 Flowchart of inclusion of study participants medical record. All presented data were post-bronchodilator data.

\section{Statistical analysis}

All statistical analyses were used IBM SPSS statistics Version 19. Categorical and continuous variables were compared using the chi-square and Mann-Whitney U tests, respectively. One-way analysis of variance (ANOVA) was used for between-group comparison of pulmonary obstruction severity, which was graded using the GOLD classification. Cox regression analysis was used for the time to the first emergency room visit or first readmission after discharge. Statistical significance was set as $\mathrm{P}<0.05$.

\section{Results}

There were 111 participants admitted for AECOPD who were potentially eligible. After screening based on the exclusion criteria and willingness to participate, we finally enrolled 43 participants (Fig. 1). Table 1 presented the demographic characteristics of the participants. Among the 43 participants, 31 (72.1\%) participants belonged to HGSw group. The HGS was significantly lower in HGSw than non-HGSw group $(22.1 \pm 4.1 \mathrm{~kg}$ vs. $33.7 \pm 3.1 \mathrm{~kg}$, $P<0.001)$. There were no between-group differences in age; sex; and comorbidities, including hypertension, diabetes, and heart diseases (coronary artery disease and valvular heart disease) (Table 1). However, compared with the HGSw group, the non-HGSw group had more

Table 1 Demographic characteristics of the participants

\begin{tabular}{llll}
\hline & Total $(\mathbf{n}=\mathbf{4 3})$ & HGSw $(\mathbf{n}=\mathbf{3 1})$ & Non-HGSw (n=12) \\
\hline Gender(M/F) & $(40 / 3)$ & $28 / 3$ & $12 / 0$ \\
Age & $72.3 \pm 9.2$ & $75.2 \pm 7.3$ & $65.1 \pm 9.8$ \\
Smoking (+/-/ex) n(\%) & $9 / 3 / 31(20.9 / 7 / 72.1)$ & $3 / 3 / 25(9.7 / 9.7 / 80.6)$ & $6 / 0 / 6(50 / 0 / 50)^{*}$ \\
Hypertension n(\%) & $18(41.9)$ & $14(45.2)$ & $4(33.3)$ \\
CVA n(\%) & $1(2.3)$ & $1(3.2)$ & $0(0)$ \\
DM n(\%) & $8(18.6)$ & $5(16.1)$ & $3(25.0)$ \\
Heart disease $n(\%)$ & $10(23.3)$ & $7(22.6)$ & $3(25.0)$ \\
CAD & $8(18.6)$ & $5(16.1)$ & $3(25.0)$ \\
VHD & $2(4.6)$ & $2(6.4)$ & $0(0)$ \\
CKD n(\%) & $1(2.3)$ & $1(3.2)$ & $0(0)$ \\
Cancer n(\%) & $2(4.7)$ & $2(6.5)$ & $0(0)$ \\
Exacerbation in previous year & $0.67 \pm 1.36$ & $0.74 \pm 1.53$ & $0.50 \pm 0.80$ \\
BMI (kg/m $\left.{ }^{2}\right)$ & $23.3 \pm 4.3$ & $22.3 \pm 4.2$ & $25.8 \pm 3.6^{*}$ \\
SMI (kg/m ${ }^{2}$ ) & $17.2 \pm 2.0$ & $16.5 \pm 1.8$ & $18.8 \pm 1.3^{*}$ \\
HGS (kg) & $25.3 \pm 6.5$ & $22.1 \pm 4.1$ & $33.7 \pm 3.1^{*}$ \\
Hospitalization duration (day) & $8.2 \pm 5.2$ & $8.84 \pm 5.8$ & $6.5 \pm 2.4$ \\
\hline
\end{tabular}

BMI, body mass index; CKD, chronic kidney disease; CVA, cerebrovascular accident; DM, diabetes mellitus; ex, ex-smoker; F, female; HGS, handgrip strength; HGSw, handgrip strength weakness; $M$, male; SMI, smooth muscle index

* Significant difference within groups HGSw vs. non-HGSw $(P<0.05)$ 
active smokers $(9.7 \%$ vs. $50 \%, P=0.003)$. As expected, BMI and SMI were significantly higher in the non-HGSw group than in the HGSw group. But all participants did not reach the criteria of sarcopenia.

Nearly total participants (41/43, 95.3\%) ever had lung function tests to confirm the diagnosis of COPD. Only two of them, belonged to HGSw group, had no adequate lung function data because they only achieved submaximal effort. 30 participants had lung function data within one year of recruitment. 21(67.7\%) and 9(75\%) participants were in the HGSw and non-HGSw groups, respectively (Additional file 1: Table S1). $\mathrm{FEV}_{1}, \mathrm{FEV}_{1}$ predicted $\%$, forced vital volume (FVC), and FVC predicted \% were significantly lower in the HGSw group than in the nonHGSw group. There was significant difference in the severity of GOLD grade between HGSw and non-HGSw groups $(P=0.002)$ (Additional file 1: Table S1).

There was no significant between-group difference in the CAT score at admission $\left(\mathrm{CAT}_{\mathrm{ad}}\right)$ and 3 months after index admission $\left(\mathrm{CAT}_{3 \mathrm{~m}}\right)(10.2 \pm 4.3$ vs $13.8 \pm 5.9$, $P=0.272$ ) (Table 2). Significantly clinical difference between $\mathrm{CAT}_{\mathrm{ad}}$ and $\mathrm{CAT}_{3 \mathrm{~m}}$ was defined as the difference with equal or more than 2 . It was not significantly different between HGSw and non-HGSw groups $(35.5 \%$ vs. $41.7 \%, P=0.757)$. Compared with non-HGSw group, the HGSw group showed significantly higher rates of emergency room visits within $6(0.81 \pm 1.30$ vs. $0.08 \pm 0.29$, $P=0.045), \quad 9 \quad(1.26 \pm 1.59$ vs. $0.17 \pm 0.38, P=0.019)$, and 12 months after index admission $(1.48 \pm 1.86$ vs. $0.25 \pm 0.62, P=0.027)$. However, it did not achieve significant differences in the readmission rates within 3,6 , 9 or 12 months between HGSw and non-HGSw groups
(Table 2, Fig. 2). There was a trend to have higher admission rate within 9 and 12 months in HGSw group, even though there was no statistical significance $(0.77 \pm 1.38$ vs. $0.08 \pm 0.29, P=0.064 ; 0.94 \pm 1.56$ vs. $0.08 \pm 0.29$, $P=0.062$, respectively). The time to the first emergency room visit or first readmission after discharge was not significantly early in HGSw group, compared to nonHGSw group (Additional file 2: Fig. S1).

\section{Discussion}

Martinez et al. reported HGS was associated with exacerbation risk in cross-sectional and longitudinal analyses [18]. However, the relationship of inpatient HGS measurement with further exacerbation risk was little investigated. Regarding physical weakness and respiratory distress in admission, HGS assessment is rarely recommended at acute stage of AECOPD admission, though there is small-scale studies reported about HGS in intensive care and respiratory failure [24]. We observed an association of HGSw with emergency department visits within 6 to 12 months after index admission, which could be possibly related to higher admission rates in the subsequent 9 to 12 months. This suggests that HGSw could be associated with the risk of further AECOPD requiring medical emergency or admission care.

The study about HGS measurement in ICU suggested HGS data might vary as clinical course changed [24]. There might be time-dependent about HGS measurement. The reason that we chose early stage of admissions due to COPDAE, was that HGS was feasible in hospitalized patients even though in intensive care unit [24]. Even if HGS is measured at pre-discharge stage, it also

Table 2 CAT score on admission and after three months, as well as the rate of emergency room visits and admissions within three, six, and twelve months after index admission

\begin{tabular}{lllll}
\hline & Total $(\mathbf{n}=\mathbf{4 3})$ & HGSw $(\mathbf{n}=\mathbf{3 1})$ & non-HGSw $(\mathbf{n}=\mathbf{1 2})$ & $\boldsymbol{P}$ \\
\hline CAT $_{\mathrm{ad}}$ & $16.6 \pm 4.3$ & $16.7 \pm 4.3$ & $16.5 \pm 4.7$ & 0.817 \\
$\mathrm{CAT}_{3 \mathrm{~m}}$ & $12.9 \pm 5.6$ & $13.8 \pm 5.9$ & $10.2 \pm 4.3$ & 0.272 \\
$\mathrm{CAT}_{\mathrm{ad}-3 \mathrm{~m}} \geq 2 \mathrm{n}(\%)$ & $16(37.2)$ & $11(35.5)$ & $5(41.7)$ & 0.737 \\
$\mathrm{ER}_{3 \mathrm{~m}}$ & $0.20 \pm 0.46$ & $0.26 \pm 0.51$ & $0.08 \pm 0.29$ & 0.279 \\
Admission $_{3 \mathrm{~m}}$ & $0.20 \pm 0.51$ & $0.26 \pm 0.58$ & $0.08 \pm 0.29$ & 0.364 \\
ER $_{6 \mathrm{~m}}$ & $0.60 \pm 1.15$ & $0.81 \pm 1.30$ & $0.08 \pm 0.29$ & 0.045 \\
Admission $_{6 \mathrm{~m}}$ & $0.34 \pm 0.81$ & $0.45 \pm 0.93$ & $0.08 \pm 0.29$ & 0.188 \\
ER $_{9 m}$ & $0.95 \pm 1.44$ & $1.26 \pm 1.59$ & $0.17 \pm 0.38$ & 0.019 \\
Admission $_{9 \mathrm{~m}}$ & $0.58 \pm 1.21$ & $0.77 \pm 1.38$ & $0.08 \pm 0.29$ & 0.064 \\
ER $_{12 \mathrm{~m}}$ & $1.13 \pm 1.69$ & $1.48 \pm 1.86$ & $0.25 \pm 0.62$ & 0.027 \\
Admission $_{12 m}$ & $0.69 \pm 1.38$ & $0.94 \pm 1.56$ & $0.08 \pm 0.29$ & 0.062 \\
\hline
\end{tabular}

Admission $_{3 \mathrm{~m}}$ : admission during three months after index admission; Admission ${ }_{6 \mathrm{~m}}$ : admission during 6 months after index admission; Admission $_{9 \mathrm{~m}}$ : admission during 6 months after index admission; Admission ${ }_{12 \mathrm{~m}}$ : admission during 12 months after index admission; CAT: chronic obstructive pulmonary disease assessment test; CAT ${ }_{\text {ad }}$ : CAT on admission; $\mathrm{CAT}_{3 \mathrm{~m}}$ : CAT three months after index admission; $\mathrm{CAT}_{\mathrm{ad}-3 \mathrm{~m}}$ : the difference of $\mathrm{CAT}_{\mathrm{ad}}$ minus $\mathrm{CAT}_{3 \mathrm{~m}}$; $\mathrm{ER}_{3 \mathrm{~m}}$ : emergency room visits during three months after index admission; $\mathrm{ER}_{\mathrm{m}}$ : emergency room visit during 6 months after index admission; $\mathrm{ER}_{\mathrm{m}}$ : emergency room visit during 6 months after index admission; $\mathrm{ER}_{12 \mathrm{~m}}$ : emergency room visit during 12 months after index admission; HGS, handgrip strength; HGSw, handgrip strength 


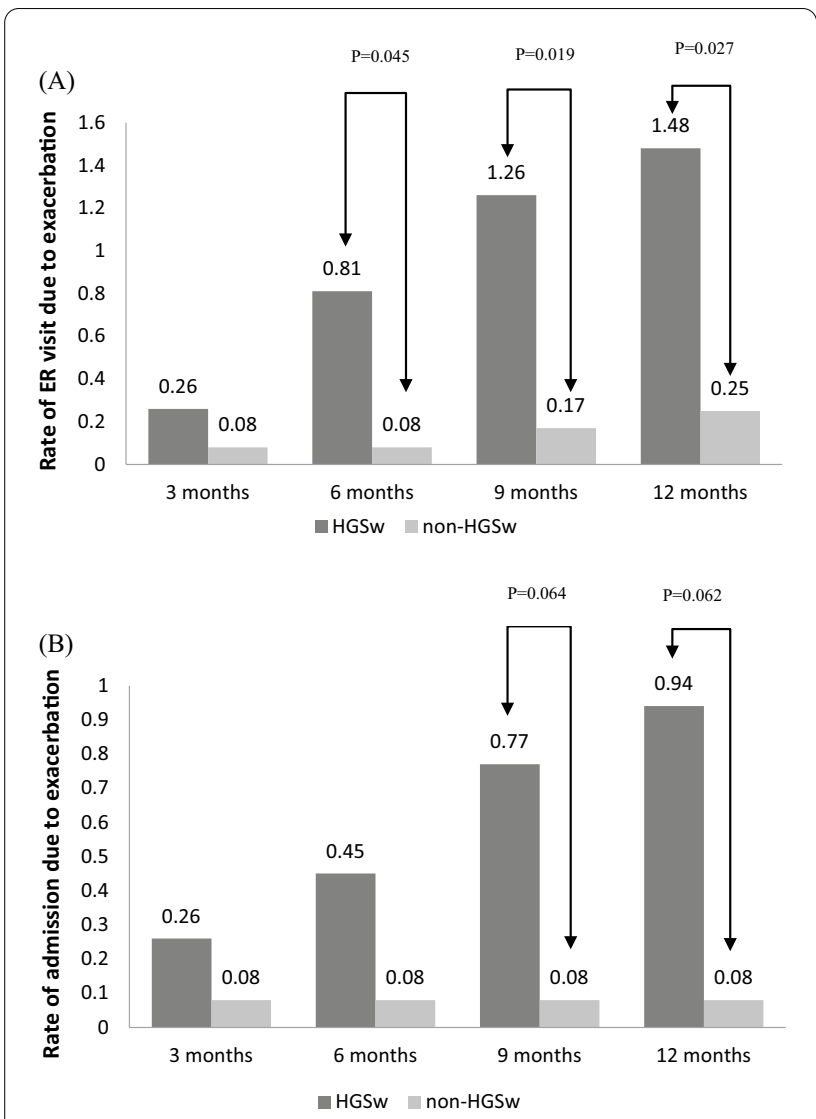

Fig. 2 Rate of exacerbations requiring emergency room visit and admission within three, six, nine, and twelve months of the index admission. Abbreviation: ER: emergency room; HGSw: handgrip strength weakness. (A) The rates of emergency room visits within 6,9 , and 12 months after index admission were significantly higher in the HGSw group than in the non-HGSw group. (B) It did not achieve significant differences in the readmission rates within 3, 6, 9 or 12 months between HGSw and non-HGSw groups. There was a trend to have higher admission rate within 9 and 12 months in HGSW group, even though there was no statistical significance

might be confounding by hospital stay, physical inactivity and other possible complications. And another possible benefit of HGS measurement in early admission is to provide the information of muscle weakness early and might arrange pulmonary rehabilitation in adequate timing of hospital stay.

The exacerbation risk is associated with the exacerbation history within the previous year and COPD GOLD grading [25]. However, we observed no between-group difference in the exacerbation history in the previous year. The airflow limitation degree could confound the relationship between HGSw and further exacerbation. However, lung function tests are not routinely recommended in the acute stage of AECOPD [1]. Lung function might be underestimated in the acute stage of patients showing insufficient effort and cooperation due to physical weakness. A similar concern could be associated with HGS. Nonetheless, even without the data of lung function tests, the present study showed that inpatient HGS measurement might be a predictor of further exacerbation.

Kaymaz et al. [26] reported a significant association of upper limb muscle strength with exercise capacity, dyspnea sensation, and quality of life in patients with severe COPD. Impaired upper limb muscle strength might be indicative of HGS weakness. Consistent with this, HGS is significantly associated with exacerbation rates and the severity of airflow obstruction among patients with stable COPD [16-18]. In addition to upper limb muscle strength, HGS is associated with lower limb strength and the 6-min walk distance [8]. HGS weakness was also reported to associate with increased mortality risk [27]. We observed a correlation of HGS weakness with the risk COPD re-exacerbation rates in need of emergency care from half to one year, and it possibly increased re-admission rate of exacerbation. HGS weakness of inpatients, admitted due to AECOPD, might be a predictor of exacerbation risk in the next year even in the status of lacking lung function data. Upper limb training, which could improve arm function and reduce symptoms in patients with COPD, should be considered for patients with HGSw and difficulties in daily arm activities [28-30]. Therefore, the HGS of inpatients might not only provide additional treatment clues regarding pulmonary rehabilitation but also act as a follow-up parameter.

This study has several limitations. First, the study had a small number of participants. The statistical power was limited. And we excluded patients with apparent fluid overload and severe exacerbation under NIPPV use on admission, which may not reflect the real population. There is a need for future large-scale studies to yield more comprehensive results. Second, the report showed $\mathrm{BMI}$ and skeletal muscle index were significantly different between HGSw and non-HGSw groups. However, the measurement of body weight and height at stable gesture might not be feasible on the scenarios of the first admission days due to acute stage of exacerbation. The study designed to investigate the relationship of handgrip strength in acute stage of admissions on further exacerbation subsequently one year. Therefore, we focused on the variable of handgrip strength to analysis in our study. And Maritnez et al. in 2017 about HGS in COPD, used regression models adjusted for multiple variables, which reported that HGS in stable patients was associated with exacerbation risk [18]. Third, the timing and cooperation of measuring HGS might be confounding factors in acute stage of AECOPD admission. 


\section{Conclusions}

In conclusion, we observed that HGSw in inpatients with AECOPD was associated with a higher risk of further exacerbations, not only providing the information of limb muscle strength.

\begin{abstract}
Abbreviations
HGS: Handgrip strength; COPD: Chronic obstructive pulmonary disease; FEV Forced expiratory volume in one second; BMl: Body mass index; AECOPD: Acute exacerbation of COPD; NIPPV: Noninvasive positive pressure ventilators; CAT: COPD assessment test; EWGSOP: European Working Group on Sarcopenia in Older People; BIA: Bioelectrical impedance analyzer; SMI: Skeletal muscle index; FVC: Forced vital volume; HGSw: HGS weakness; KNHANES: Korean National Health and Nutrition Examination Survey.
\end{abstract}

\section{Supplementary Information}

The online version contains supplementary material available at https://doi. org/10.1186/s12890-021-01610-7.

Additional file 1: Table S1. Post-bronchodilator lung function test and COPD GOLD stage of the participants within one year before recruitment

Additional file 2: Figure S1. Cox regression analysis of (A) time to first emergency room visit and (B) time to first readmission after discharge

\section{Acknowledgements}

Not applicable.

\section{Authors' contributions}

C-TL: Conceptualization, methodology, validation, investigation, resources, writing - original draft. P-HW: Conceptualization, methodology, validation, resources, writing - review \& editing, Funding acquisition. Both authors read and approved the final manuscript.

\section{Funding}

This study was supported by Far Eastern Memorial hospital (FEMH-2018-C-029).

\section{Availability of data and materials}

The data that support the findings of this study are available from the corresponding author, [P.H.W], upon reasonable request.

\section{Declarations}

\section{Ethics approval and consent to participate}

The Institutional Review Board of Far Eastern Memorial Hospital approved this study (IRB 106099-E). Participants had to sign Informed consent before initiating the study.

\section{Consent for publication \\ Not applicable.}

\section{Competing interests}

All authors declare no financial, professional, or other personal interests of any nature or kind in a related product, service, and/or company.

\section{Author details}

${ }^{1}$ Division of Pulmonology, Department of Internal Medicine, Far Eastern Memorial Hospital, New Taipei City 220, Taiwan, ROC. ${ }^{2}$ Department of Nursing, Oriental Institute of Technology, New Taipei City, Taiwan, ROC.

Received: 19 May 2021 Accepted: 13 July 2021

Published online: 21 July 2021
References

1. 2021 Global strategy for prevention, diagnosis and management of COPD. https://goldcopd.org/2021-gold-reports/

2. Lange P, Celli B, Agustí A, Boje Jensen G, Divo M, Faner R, Guerra S, Marott $J$, Martinez FD, Martinez-Camblor P, et al. Lung-function trajectories leading to chronic obstructive pulmonary disease. N Eng J Med. 2015:373(2):111-22

3. Mathers CD, Loncar D. Projections of global mortality and burden of disease from 2002 to 2030. PLoS Med. 2006:3(11):e442.

4. Cheng SL, Chan MC, Wang CC, Lin CH, Wang HC, Hsu JY, Hang LW, Chang CJ, Perng DW, Yu CJ. COPD in Taiwan: a National Epidemiology Survey. Int J Chron Obstruct Pulmon Dis. 2015:10:2459-67.

5. Causes of death statistics. https://www.mohw.gov.tw/lp-3267-2.html.

6. Barnes PJ, Celli BR. Systemic manifestations and comorbidities of COPD. Eur Respir J. 2009;33(5):1165-85.

7. Hamilton AL, Killian KJ, Summers E, Jones NL. Muscle strength, symptom intensity, and exercise capacity in patients with cardiorespiratory disorders. Am J Respir Crit Care Med. 1995;152(6 Pt 1):2021-31.

8. Gosselink R, Troosters T, Decramer M. Peripheral muscle weakness contributes to exercise limitation in COPD. Am J Respir Crit Care Med. 1996;153(3):976-80.

9. Bernard SLP, Whittom F, Carrier G, Jobin J, Belleau R, Maltais F. Peripheral muscle weakness in patients with chronic obstructive pulmonary disease. Am J Respir Crit Care Med. 1998;158(2):629-34.

10. Franssen FM, Broekhuizen $R$, Janssen PP, Wouters EF, Schols AM. Limb muscle dysfunction in COPD: effects of muscle wasting and exercise training. Med Sci Sports Exerc. 2005;37(1):2-9.

11. Miranda EF, Malaguti C, Corso SD. Peripheral muscle dysfunction in COPD: lower limbs versus upper limbs. J Bras Pneumol. 2011:37(3):380-8.

12. Fonseca J, Machado FVC, Santin LC, Andrello AC, Schneider LP, Fernandes Belo L, Rodrigues A, Fernandes Rugila D, Furlanetto KC, Hernandes NA et al. Handgrip Strength as a Reflection of General Muscle Strength in Chronic Obstructive Pulmonary Disease. COPD 2021;1-12.

13. Ling CH, Taekema D, de Craen AJ, Gussekloo J, Westendorp RG, Maier AB. Handgrip strength and mortality in the oldest old population: the Leiden 85-plus study. CMAJ. 2010;182(5):429-35.

14. Rantanen TVS, Ferrucci L, Heikkinen E, Fried LP, Guralnik JM. Handgrip strength and cause-specific and total mortality in older disabled women: exploring the mechanism. J Am Geriatr Soc. 2003;51(5):636-41.

15. Shah S, Nahar P, Vaidya S, Salvi S. Upper limb muscle strength \& endurance in chronic obstructive pulmonary disease. Indian J Med Res. 2013:138(4):492-6.

16. Strandkvist VJ, Backman H, Röding J, Stridsman C, Lindberg A. Hand grip strength is associated with forced expiratory volume in 1 second among subjects with COPD: report from a population-based cohort study. Int J Chron Obstruct Pulmon Dis. 2016:11:2527-34.

17. Han $\mathrm{CH}$, Chung JH. Association between hand grip strength and spirometric parameters: Korean National health and Nutrition Examination Survey (KNHANES). J Thorac Dis. 2018;10(11):6002-9.

18. Martinez CH, Diaz AA, Meldrum CA, McDonald M-LN, Murray S, Kinney GL, Hokanson JE, Curtis JL, Bowler RP, Han MK, et al. Handgrip Strength in chronic obstructive pulmonary disease. Associations with acute exacerbations and body composition. Ann Am Thorac Soc. 2017;14(11):1638-45.

19. Turan Z, Özyemişçi Taşkiran Ö, Erden Z, Köktürk N, Kaymak Karataş G. Does hand grip strength decrease in chronic obstructive pulmonary disease exacerbation? A cross-sectional study. Turk J Med Sci. 2019;49(3):802-808.

20. Mialich MS, Sicchieri JMF, Jordao Junior AA. Analysis of body composition: a critical review of the use of bioelectrical impedance analysis. Int J Clin Nutr. 2014;2(1):1-10.

21. Coppini LZ, Waitzberg DL, Campos AC. Limitations and validation of bioelectrical impedance analysis in morbidly obese patients. Curr Opin Clin Nutr Metab Care. 2005;8(3):329-32.

22. Peolsson A, Hedlund R, Oberg B. Intra- and inter-tester reliability and reference values for hand strength. J Rehabil Med. 2001;33(1):36-41.

23. Cruz-Jentoft AJ, Baeyens JP, Bauer JM, Boirie Y, Cederholm T, Landi F, Martin FC, Michel JP, Rolland Y, Schneider SM, et al. Sarcopenia: European consensus on definition and diagnosis: Report of the European Working Group on Sarcopenia in Older People. Age Ageing. 2010;39(4):412-23. 
24. Mohamed-Hussein AAR, Makhlouf HA, Selim ZI, Gamaleldin SW. Association between hand grip strength with weaning and intensive care outcomes in COPD patients: A pilot study. Clin Respir J. 2018;12(10):2475-9.

25. Hurst JR, Vestbo J, Anzueto A, Locantore N, Müllerova H, Tal-Singer R, Miller B, Lomas DA, Agusti A, Macnee W, et al. Susceptibility to exacerbation in chronic obstructive pulmonary disease. N Engl J Med. 2010;363(12):1128-38.

26. Kaymaz D, Candemir I, Ergün P, Demir N, Taşdemir F, Demir P. Relation between upper-limb muscle strength with exercise capacity, quality of life and dyspnea in patients with severe chronic obstructive pulmonary disease. Clin Respir J. 2018;12(3):1257-63.

27. Burtin C, ter Riet G, Puhan MA, Waschki B, Garcia-Aymerich J, Pinto-Plata V, Celli B, Watz H, Spruit MA. Handgrip weakness and mortality risk in COPD: a multicentre analysis. Thorax. 2016;71(1):86-7.
28. Costi S, Crisafulli E, Degli Antoni F, Beneventi C, Fabbri LM, Clini EM. Effects of unsupported upper extremity exercise training in patients with COPD: a randomized clinical trial. Chest. 2009;136(2):387-95.

29. Janaudis-Ferreira T, Hill K, Goldstein RS, Robles-Ribeiro P, Beauchamp MK, Dolmage TE, Wadell K, Brooks D. Resistance arm training in patients with COPD: a randomized controlled trial. Chest. 2011;139(1):151-8.

30. McKeough ZJ, Bye PT, Alison JA. Arm exercise training in chronic obstructive pulmonary disease: a randomised controlled trial. Chron Respir Dis. 2012;9(3):153-62.

\section{Publisher's Note}

Springer Nature remains neutral with regard to jurisdictional claims in published maps and institutional affiliations.
Ready to submit your research? Choose BMC and benefit from:

- fast, convenient online submission

- thorough peer review by experienced researchers in your field

- rapid publication on acceptance

- support for research data, including large and complex data types

- gold Open Access which fosters wider collaboration and increased citations

- maximum visibility for your research: over 100M website views per year

At BMC, research is always in progress.

Learn more biomedcentral.com/submissions 